\title{
The Substitution of Cysteine 17 of Recombinant Human G-CSF with Alanine Greatly Enhanced its Stability
}

\author{
Masaharu Ishikawa, Hiroshi Iijima*, Rika Satake-Ishikawa, Haruhiko Tsumura, Akihiro \\ Iwamatsu*, Toshihiko Kadoya, Yoshihiro Shimada, Hiromi Fukamachi, Keiko Kobayashi, \\ Shigeru Matsuki ${ }^{\dagger}$, and Katsuhiko Asano \\ Pharmaceutical Laboratory, and ${ }^{*}$ Central Laboratories for Key Technology, Kirin Brewery Co., Ltd. Souja- \\ machi, Maebashi, Gunma, 371, Japan
}

Key words: cysteine/granulocyte-colony stimulating factor/site-directed mutagenesis/thermostability

\begin{abstract}
Human recombinant granulocyte-colony stimulating factor (rhG-CSF) has one free cysteine at position 17 and has two disulfide bridges (Cys36-Cys42 and Cys64-Cys74). The Cys17 of rhG-CSF was substituted with Gly, Ala, Ser, He, Tyr, Arg, and Pro, or deleted using site-directed mutagenesis in order to improve its thermostability. With the exception of Pro17-rhG-CSF, all mutant proteins retained biological activity which promotes the growth of mouse bone marrow cells in vitro. Among these mutant proteins, Ala17-rhG-CSF had more than 5 times higher stability than rhG-CSF. But Ser17-rhG-CSF had almost same stability as rhG-CSF and other mutant proteins had only lower stability.
\end{abstract}

Human G-CSF (hG-CSF) is a hemopoietic factor which regulates neutrophil proliferation and differentiation (13). The cDNA encoding hG-CSF was cloned (15, 19) and large scale production of the recombinant human G-CSF (rhG-CSF) was obtained using genetically engineered Escherichia coli (19). rhG-CSF is also capable of supporting the formation of granulocytic colonies from bone marrow cells and is undergoing clinical testing for cancer patients with drug- or irradiation-induced myelosuppression $(14,22)$.

rhG-CSF has one free cysteine at position 17 and has two disulfide bridges (Cys36-Cys42 and Cys64-Cys74) (9). It is known that the free cysteines in T4 Lysozyme (16), Interferon- $\beta$ (11) and Interleukin-2 (IL-2) (2) are involved in intermolecular thiol/disulfide interchange leading to inactive oligomers. Mutagenic replacement of unpaired Cys54 of T4 Lysozyme with Thr or Val generated one exhibiting enhanced stability toward irreversible thermal inactivation. In the case of IL-2, substitution of Cys 125 with Ser or Ala yielded one with greater stability. In the case of rhG-CSF, previous studies showed that the substitution of unpaired Cys 17 of rhGCSF with Ser did not change its conformational stability (23) and that the 17 th residue of murine G-CSF was serine (18).

In this report, we substituted the unpaired Cys17 of rhG-CSF with several other amino acids or deleted and

\footnotetext{
${ }^{\dagger}$ To whom correspondence should be addressed.
}

Abbreviations: G-CSF, granulocyte-colony stimulating factor; $\mathrm{CD}$, circular dichroism. compared their stabilities. Among those mutant proteins, Ala17-rhG-CSF was found to have more than 5 times greater stability than rhG-CSF.

\section{MATERIALS AND METHODS}

Materials. E. coli DNA polymerase I Klenow fragment, T4 polynucleotide kinase, T4 DNA polymerase, T4 DNA ligase, T4 gene 32 protein and restriction enzymes were purchased from Boehringer Mannheim, Takara Shuzo or BioRad. Bacteriophage M13mp19 (24) was obtained from Takara Shuzo.

Recombinant DNA methods. Recombinant DNA methods were performed as described by Manniatis et al. (10).

Synthesis of oligonucleotide. Oligonucleotides were prepared by the phosphoramidite method (3) using a DNA synthesizer (Applied Biosystems).

Site-directed mutagenesis of human G-CSF gene. An hGCSF expression plasmid, pCFM 1156 hG-CSF, containing a chemically synthesized G-CSF gene (20), was digested with $X b a \mathrm{I}$ and $E c o$ RI. The smaller $X b a \mathrm{I}-E c o$ RI fragment was inserted between the $X b a \mathrm{I}$ and $E c o$ RI sites of bacteriophage M13mp19. The resulting M13 bacteriophage contains the hGCSF gene. Site-directed mutagenesis of hG-CSF gene using an oligonucleotide was performed as described by Zoller $e t$ al. (25) or Kunkel et al. (7). The nucleotide sequence of the mutated hG-CSF genes were confirmed by the dideoxy sequencing method (12). To insert the mutated hG-CSF genes into the expression plasmid, an EcoRI site located at the $\mathbf{3}^{\prime}$ end of human G-CSF gene was changed to XhoI site by site-directed 
mutagenesis. The resulting M13 bacteriophages containing the mutated hG-CSF genes were digested with $X b a \mathrm{I}$ and $X h o I$. The small $X b a$ I and $X h o I$ fragments containing the mutated hG-CSF genes were ligated with the large $X b a I-X h o I$ fragment of the hG-CSF expression plasmid, pCFM536 (19).

Production and purification of rhG-CSF mutant proteins. Expression of the mutated human G-CSF genes in $E$. coli and purification of mutant proteins of rhG-CSF were performed as previously described (21).

Biological activity. Biological activities of rhG-CSF mutant proteins were measured by the uptake of $\left[{ }^{3} \mathrm{H}\right]$-thymidine into mouse bone marrow cells following the procedure of Ralph et al. (17) with some modifications. In brief, low-density $\left(<1.077 \mathrm{~g} / \mathrm{cm}^{-3}\right)$ nonadherent bone marrow cells from female Balb/c mice were incubated for 3 days in dilutions of rhG-CSF mutant proteins in supplemented McCoy's 5a medium $\left(10 \%\right.$ fetal calf serum). The cell concentration was $8 \times 10^{4}$ cells per well in a volume of $0.2 \mathrm{ml}$ in 96 well flat-bottom plates. After the incubation, the cells were pulse-labelled with ${ }^{3} \mathrm{H}$-thymidine for 5 hours ( $1 \mu \mathrm{Ci}$ per well), harvested on glass fiber filters and assayed for radioactivity using a liquid-scintillation counter. Biological activities of rhG-CSF mutant proteins were calculated by a parallel line assay. A purified preparation of rhG-CSF, quantified by the mouse bone marrow colony assay, was used as a standard.

Amino acid sequence analysis. The N-terminal sequences of rhG-CSF and its mutant proteins were determined using a gas-phase sequencer (Applied Biosystems model 470A) follow-

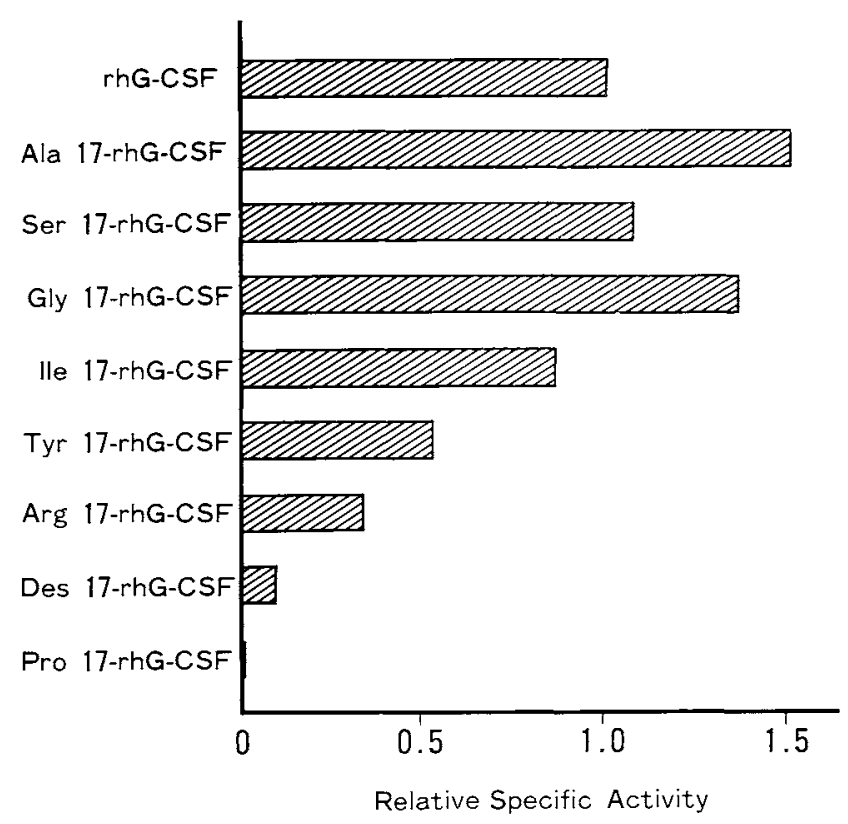

Fig. 1. Comparison of relative specific activities of rhG-CSF mutant proteins.

Relative specific activities are expressed using a value of 1.0 for rhGCSF. ing the procedure of Hewick et al. (6). The phenylthiohydantoin derivatives (PTH-amino acids) obtained were analyzed by a reverse phase HPLC chromatography under the conditions described previously (1).

Amino acid composition. Proteins were hydrolyzed for $24 \mathrm{hr}$ in $6 \mathrm{~N} \mathrm{HCl}$ (constant boiling) containing $0.2 \%$ phenol at $110^{\circ} \mathrm{C}$ in evacuated tubes. Amino acid analysis was carried out with a Hitachi 835 analyzer. Cysteine and half cystine were determined as S-carboxymethyl cysteine after reduction and S-carboxymethylation of the protein according to the method of Crestfield et al. (4).

Circular dichroic $(C D)$ spectrometry. The CD spectra of the proteins were measured with a Jasco J600 spectropolarimeter. Spectra were recorded at $15^{\circ} \mathrm{C}$ using a $0.1 \mathrm{~cm}$-path-length cell with $1 \mathrm{~nm}$ band-width. Measurements were carried out using approximately $0.5 \mathrm{mg} / \mathrm{ml}$ at $\mathrm{pH} 4.0$. The spectral data were expressed as molar ellipticity $([\theta] \mathrm{mrw})$, calculated using a mean residue weight of 104.4 (5).

Gel filtration HPLC analysis. The quantitative measurements of monomer contents of rhG-CSF mutant proteins were carried out by gel filtration analysis using a HPLC chromatography system. The column was a TSKgel-G3000SW $(7.5 \mathrm{~mm} \times 60 \mathrm{~cm})$. The solvent, used at a flow rate of 1.0 $\mathrm{ml} / \mathrm{min}$, was $10 \mathrm{mM}$ Sodium acetate buffer ( $\mathrm{pH}$ 5.4). Absorbance at $280 \mathrm{~nm}$ was used for the detection of proteins.

Other methods. SDS-polyacrylamide gel electrophoresis (SDS-PAGE) was carried out as described by Laemmli (8) using $15 \%$ polyacrylamide gels. Coomassie brilliant blue R250 was used to stain the protein bands. Protein concentration was spectrophotometrically determined by absorbance at $280 \mathrm{~nm}$.

\section{RESULTS AND DISCUSSION}

Preparation of rhG-CSF mutant proteins. The cysteine situated at position 17 of the chemically synthesized hG-CSF gene was replaced by Gly, Ala, Ser, Ile, Tyr, Arg and Pro, or deleted by site-directed mutagenesis using an oligonucleotide. The mutated hG-CSF genes were expressed in $E$. coli. The mutant rhG-CSF proteins were extracted from $E$. coli cells and purified to homogeneity except Pro17-rhG-CSF. Pro17-rhG-CSF could be expressed in the cells, but could not be completely purified because it formed aggregation bodies during the purification process. The molecular weights

Table 1. RESIDUAL BIOLOGICAL ACtIVITIES (\%) OF ThG-CSF MUTANT PROTEINS.

\begin{tabular}{lccc}
\hline \multirow{2}{*}{ sample } & \multicolumn{3}{c}{ Residual Activity (\%) } \\
\cline { 2 - 4 } & $6 \mathrm{hr}$ & $12 \mathrm{hr}$ & $72 \mathrm{hr}$ \\
\hline rhG-CSF & 65 & 70 & 1 \\
Ala17-rhG-CSF & 99 & 116 & 54 \\
Ser17-rhG-CSF & 84 & 57 & 3 \\
\hline
\end{tabular}




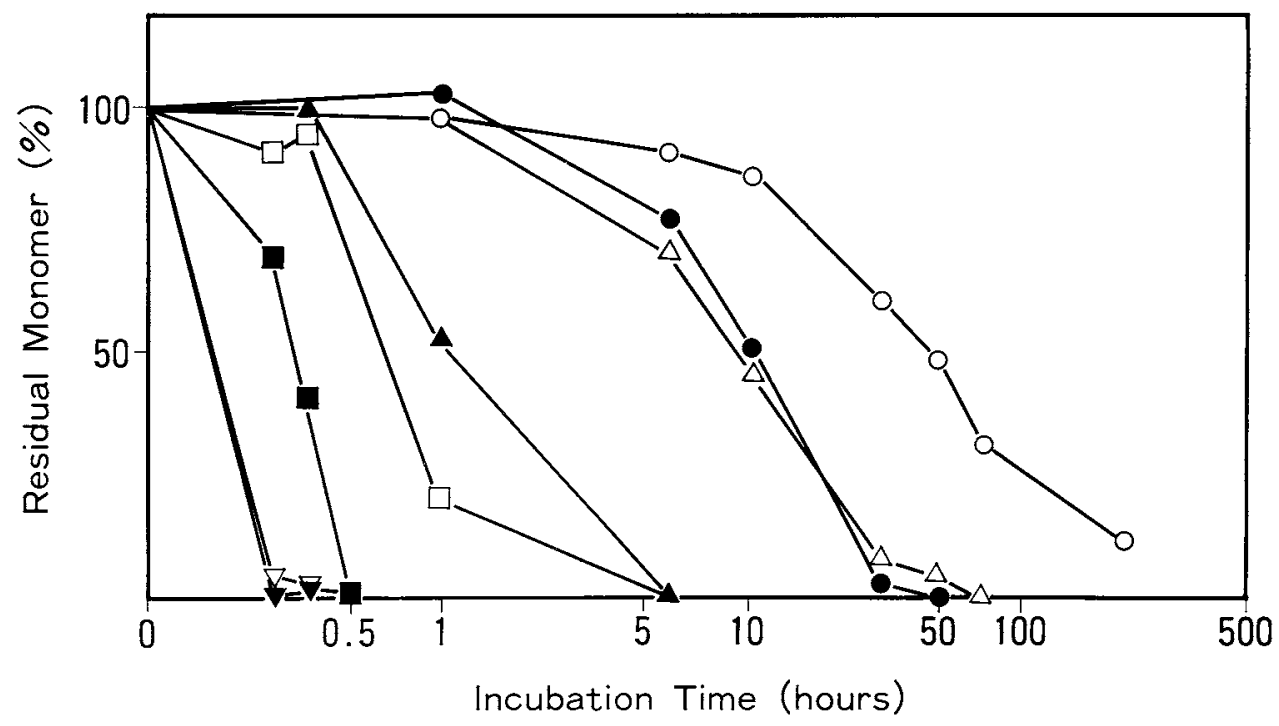

Fig. 2. Residual monomer contents $(\%)$ of rhG-CSF mutant proteins.

The residual monomer contents $(\%)$ of samples incubated at $53^{\circ} \mathrm{C}$ for various times were measured by gel filtration HPLC analysis as described in Materials and Methods.

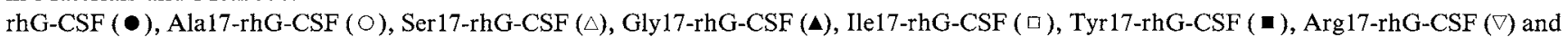
$\operatorname{Des} 17-$ rhG-CSF ( $\mathbf{v})$.

of mutant proteins as estimated by SDS-PAGE were about 19,000. The substitution or deletion of Cys17 of each mutant protein was confirmed by amino acid analysis and by $\mathrm{N}$-terminal sequence analysis (data not shown).
Biological activity of mutant proteins. Figure 1 shows the relative specific activities in vitro of mutant proteins. The biological activities in vitro of mutant proteins were determined by incorporation of $\left[{ }^{3} \mathrm{H}\right]$ thymidine into bone marrow cells of mice. With the exception

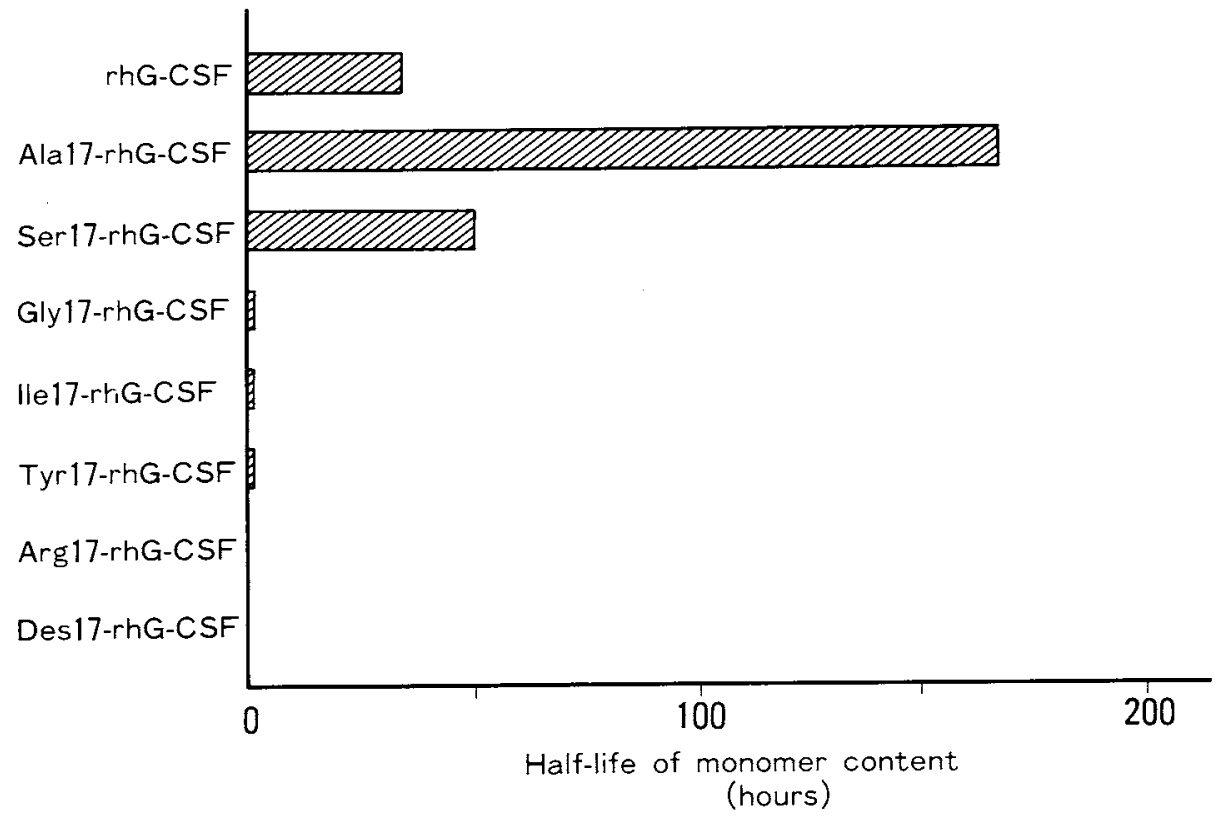

Fig. 3. Half-life times of residual monomer contents of rhG-CSF mutant proteins. Each half-life time was calculated from the data of Fig. 2. 


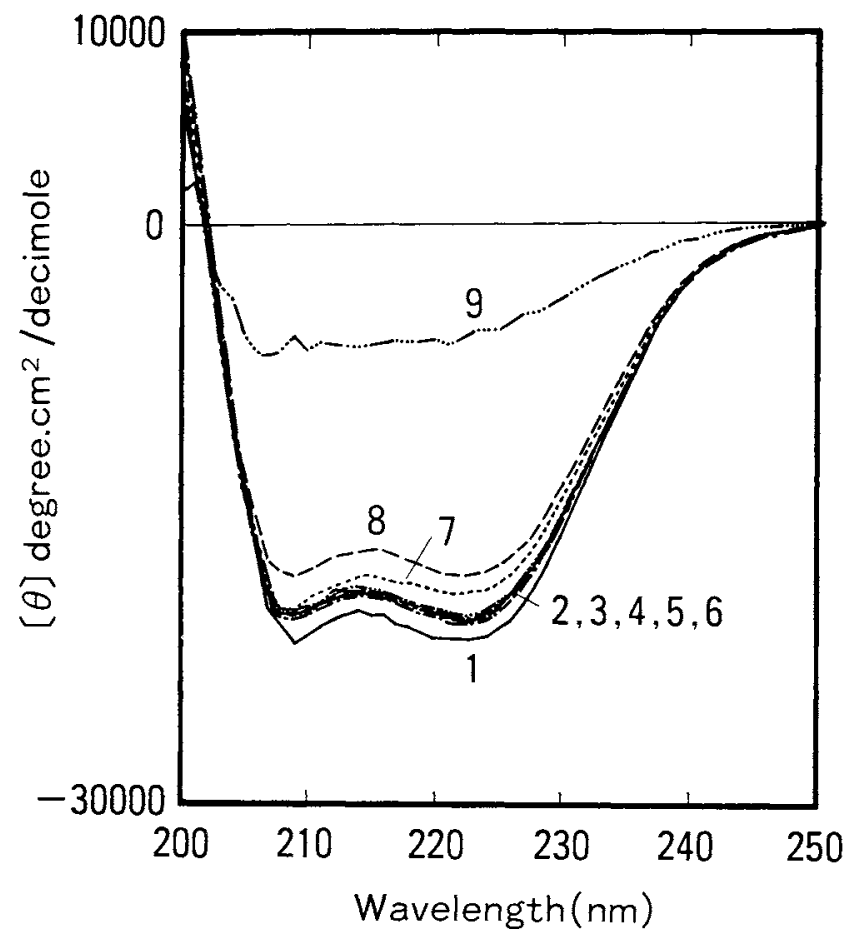

Fig. 4. CD spectra of rhG-CSF mutant proteins.

1: rhG-CSF, 2: Ala17-rhG-CSF, 3: Ser17-rhG-CSF, 4: Gly17-rhGCSF, 5: Ile17-rhG-CSF, 6: Tyr17-rhG-CSF, 7: Arg17-rhG-CSF, 8: Des17-rhG-CSF, 9: Prol7-rhG-CSF

of Pro17-rhG-CSF, they all retained biological activity in vitro. Gly17-rhG-CSF, Ala17-rhG-CSF and Ser17rhG-CSF had almost the same or higher specific biological activities than rhG-CSF, and the other mutants had lower activities. Pro17-rhG-CSF had no detectable biological activity. These results indicate that the amino acid residue at position 17 affects the biological activity in some degree but does not play an essential role.

Thermostabilities of mutant proteins. To investigate the thermostabilities of mutant proteins, they were incubated at $53^{\circ} \mathrm{C}$ and their residual biological activities were assayed. Table I shows the results with regard to rhG-CSF, Ala17-rhG-CSF and Ser17-rhG-CSF. Other mutant proteins retained less than $1 \%$ of their initial activities after $6 \mathrm{hr}$ incubation. The enhanced thermostability of Ala17-rhG-CSF was further confirmed by gel filtration HPLC analysis. The intermolecular thiol/disulfide interchange caused the formation of oligomers of rhG-CSF. In our preliminary study, we found a linear correlation between the biological activity of rhG-CSF and the amount of its monomer form (data not shown). Hence, we incubated these mutant proteins at $53^{\circ} \mathrm{C}$ and measured their residual monomer contents (\%) by gel filtration HPLC analysis. Figure 2 shows the decrease of the residual monomer content $(\%)$ of each mutant protein during the incubation at $53^{\circ} \mathrm{C}$.
We calculated the half-life time of the residual monomer content $(\%)$ of each mutant protein from the data of Figure 2. The half-life time of monomer content (\%) of rhG-CSF or Ser 17-rhG-CSF under these conditions was 34 hours and 50 hours, respectively. On the other hand, that of Ala17-rhG-CSF was more than 168 hours (Fig. 3). These results show that the replacement of Cys 17 with Ala improved the heat-stability of rhG-CSF greatly and that not only the disulfide bond scrambling of Cys 17 but also other properties may be relevant to its heat-stability. As the CD spectra of mutant proteins except Pro17-rhG-CSF at far UV region (200-250 nm) were similar to that of rhG-CSF (Fig. 4), it is thought that those mutant proteins had similar conformations. But some conformational change of the side chain at the residue of position 17 may affect the heat-stability of rhG-CSF. More information about the structure of rhG-CSF, for instance $x$-ray diffraction data, will help to explain the relationship between the stability of $\mathrm{rhG}-$ CSF and the 17th amino acid residue in more detail.

Acknowledgment. We would like to thank Dr. E. Nishida and Dr. E.A. Hosford for their critical reading of the manuscript.

\section{REFERENCES}

1. Aoyama, H., Imamatsu, A., Dibo, G., Tsunasawa, S., and SAKIYAMA, F. (1988). An improved isocratic HPLC separation of PTH-amino acids at the subpicomole level and its application to protein sequence analysis. J. Protein Chem., 7: 191.

2. Arakawa, T., Boone, T., Davis, J.M., and Kenney, W.C. (1986). Structure of unfolded and refolded recombinant derived [Ala ${ }^{125}$ ] Interleukin 2. Biochemistry, 25: 8274-8277.

3. Beaucage, S.L. and CARuthers, M.H. (1981). Deoxynucleotide phosphoramidites. A new class of key intermediates for deoxypolynucleotide synthesis. Tetrahedron Lett., 22: 1859-1862.

4. Crestrield, A.M., Moore, S., and Stein, W.H. (1963). The preparation and enzymatic hydrolysis of reduced and S-carboxymethylated proteins. J. Biol. Chem., 238: 622-627.

5. Greenfield, N.J. and Fasman, G.D. (1969). Computed circular dichroism spectra for the evaluation of protein conformation. Biochemistry, 8: 4108-4116.

6. Hewick, R.M., Hunkapillar, M.W., Hood, L.E., and DREYER, W.J. (1981). A gas-liquid solid phase peptide and protein sequenator. J. Biol. Chem., 256: 7990-7997.

7. Kunkel, T.A., Roberts, J.D., and Zakour, R.A. (1987). Rapid and efficient site-specific mutagenesis without phenotypic selection. In Methods in Enzymology. Vol. 154, (R. Wu and L. Grossman, eds.). Academic Press, New York, pp367-382.

8. LAEMMLI, U.K. (1970). Cleavage of structural proteins during the assembly of the head of bacteriophage T4. Nature, 227: 680685.

9. LU, H., Boone, T.C., Souza, L.M., and LAI, P.H. (1989). Disulfide and secondary structures of recombinant human granulocyte colony stimulating factor. Arch. Biochem. Biophys., 268: 81-92.

10. Manniatis, T., Fritsch, E.F., and Sambrook, J. (1982). Molecular Cloning: A Laboratory Manual. Cold Spring Harbor Laboratory Press, Cold Spring Harbor, New York. 
11. Mark, D.F., Lu, S.D., Creasey, A.A., Yamamoto, R., and LIN, L.S. (1984). Site-specific mutagenesis of the human fibroblast interferon gene. Proc. Natl. Acad. Sci. USA, 81: 56625666.

12. Messing, J. (1983). New M13 vectors for cloning. In Methods in Enzymology, Vol. 101, (R. Wu, L. Grossman, and K. Moldave, eds.). Academic Press, New York, pp20-78.

13. Metcalf, D. (1986). The molecular biology and functions of the granulocyte-macrophage colony stimulating factors. Blood, 67: 257-267.

14. Morstyn, G., Campbell, L., Souza, L.M., Alton, N.K., KeEch, J., Green, M., Sheridan, W., MetCalF, D., and Fox, R. (1988). Effect of granulocyte colony stimulating factor on neutropenia induced by cytotoxic chemotherapy. Lancet, 26: 667-672.

15. Nagata, S., Tsuchiya, M., Asano, S., Kaziro, Y., Yamazaki, T., Yamamoto, O., Hirata, Y., Kubota, N., Oheda, M., Nomura, H., and ONo, M. (1986). Molecular cloning and expression of cDNA for human granulocyte colony-stimulating factor. Nature, 319: 415-418.

16. Perry, L.J. and Wetzel, R. (1986). Unpaired cysteine-54 interferes with the ability of an engineered disulfide to stabilize T4 lysozyme. Biochemistry, 25: 733-739.

17. Ralph, P., Warren, M.K., Lee, M.T., Csejtey, J., Weaver, J.F., Broxmeyer, H.E., Williams, D.E., Stanley, E.R., and KAWASAKI, E.S. (1986). Inducible production of human macrophage growth factor, CSF-1, Blood, 68: 633-639.

18. SIMPSON, R.J., NiCE, E.C., and Nicola, N.A. (1987). Structural studies on the murine granulocyte colony-stimulating factor. Biol. Chem. Hoppe-Seyler, 368: 1327-1331.
19. Souza, L.M., Boone, T.C., Gabritove, J., LaI, P.H., Zsebo, K.M., Murdock, D.C., Chazin, V.R., Bruszewski, J., Lu, H., Chen, K.K., Barendt, J., Platzer, E., Moore, M.A.S., MerteismanN, R., and WBLte, K. (1986). Recombinant human granulocyte colony-stimulating factor; effects on normal and leukemic myeloid cells. Science, 232: 61-65.

20. SouzA, L.M. (1989). Production of pluripotent granulocyte colony-stimulating factor. U.S. Patent, 4810643.

21. Tanaka, H., OKada, Y., Kawagishi, M., and Tokiwa, T. (1989). Pharmacokinetics and pharmacodynamics of recombinant human granulocyte-colony stimulating factor after intravenous and subcutaneous administration in the rat. J. Pharm. Exp. Ther., 251: 1199-1203.

22. Teshima, H., Ishikawa, J., Kitayama, H., Yamagami, T., Hiraoka, A., Nakamura, H., Shibata, H., Masaoka, T., and TAKAKU, F. (1989). Clinical effects of recombinant human granulocyte colony-stimulating factor in leukemia patents: A Phase I/II study. Exp. Hematol., 17: 853-858.

23. Wingfield, P., Benedict, R., Turcatti, G., Allet, B., Mermod, J., Delamarter, J., Simona, M., and Rose, K. (1988). Characterization of recombinant-derived granulocytecolony stimulating factor (G-CSF). Biochem. J., 256: 213-218.

24. YANNISCh-PERron, C., VIERIA, J., and MESSING, J. (1985). Improved M13 phage cloning vectors and host strains: nucleotide sequences of the M13mpl 8 and pUC19 vectors. Gene, 33: 103119.

25. Zoller, M.J. and SMith, M. (1983). Oligonucleotide-directed mutagenesis of DNA fragments cloned into M13 vectors. In Methods in Enzymology. Vol. 100, (R. Wu, L. Grossmann, and K. Moldave, eds.). Academic Press, New York, pp468-500.

(Received for publication, November 14, 1991 and in revised form, December 28, 1991) 